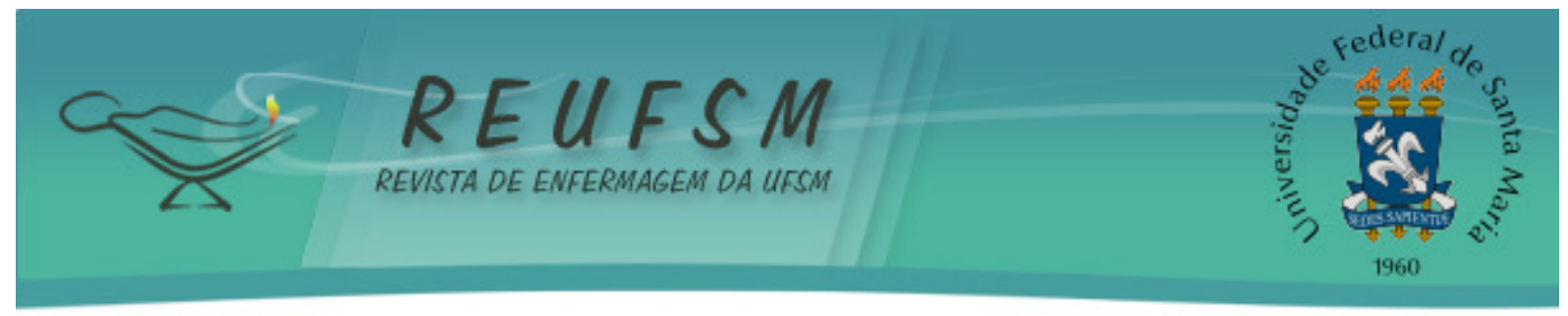

ARTIGO ORIGINAL

\title{
REPRESENTAÇÕES SOCIAIS DE ADOLESCENTES SOBRE SAÚDE-DOENÇA E INTERESSES DE PARTICIPAÇÃO EM GRUPOS EDUCATIVOS
}

\section{ADOLESCENTS' SOCIAL REPRESENTATIONS ABOUT HEALTH AND DISEASE AND INTEREST IN PARTICIPATING IN EDUCATIONAL GROUPS}

\section{REPRESENTACIONES SOCIALES DE LOS ADOLESCENTES SOBRE SALUD-ENFERMEDAD E INTERÉS DE PARTICIPACIÓN EN GRUPOS EDUCATIVOS}

\author{
Elizabeth Teixeira ${ }^{1}$ \\ Sylvia Regina Vasconcellos de Aguiar ${ }^{2}$ \\ Sarah Yasmin Pinto Leal ${ }^{3}$ \\ Marilene Gonçalves Lopes ${ }^{4}$ \\ Thais Garcia Raymond ${ }^{5}$ \\ Lidiane Ketlin Fontel Cunha ${ }^{6}$ \\ Thyago Douglas Pereira Machado ${ }^{7}$
}

Doi: $10.5902 / 217976929166$

RESUMO: Objetivos: conhecer as representações sociais sobre saúde e doença no olhar dos adolescentes. Método: pesquisa qualitativa, exploratória. Dados coletados através da técnica de associação livre de palavras e perguntas abertas, com 134 adolescentes da Unidade Saúde da Família e analisados com o olhar das representações sociais. Resultados: prevaleceu a faixa etária de 15 a 17 anos, do sexo feminino, de estudantes até a $8^{\text {a }}$ série, solteiros, renda familiar de 1 a 2 salários mínimos. A maioria nunca participou de grupos educativos. As representações sociais sobre saúde têm centralidade em alimentação, bemestar e cuidar-cuidado, quanto a doença estão centralizadas em dor e medicamento. Conclusões: as representações sociais sobre doença estão relacionadas com sentidos negativos havendo, contudo, com relação à saúde predominância positiva. Há interesse em participar de grupos educativos sobre questões relacionadas com sexualidade, drogas, processo saúde-doença, prevenção, esporte, educação e profissão.

DESCRITORES: Adolescente; Educação em saúde; Enfermagem.

ABSTRACT: Aims: to analyze points of view profiles on health and diseases. Method: exploratory, qualitative research. Data was collected with 134 adolescences from the Unity of Family Health thought free words association technic and open questions. Results: prevalence of 15 to 17 years old female students with until 8th degree, single, familiar gains in between 1 to 2 minimum salaries. Most of them had never participated on educational groups and they had shown interest of participating on Saturdays morning in groups that educate about "health, prevention and care". The social representations about health are mainly on alimentation, well been and care, concerning diseases they are mainly on pain and medication. Conclusion: the social representations are related with a sense of negativity, but concerning their relation with health it is mainly positive. There are interested of participating on educational groups with meters on sexuality, drugs, health/diseases processes, prevention, sports, educations and professions.

Descriptors: Adolescent; Health education; Nursing.

RESUMEN: Objetivos: conocer las representaciones sociales acerca de la salud y la enfermedad desde el punto de vista de los adolescentes. Método: investigación cualitativa, exploratoria. Datos recogidos, a través de la técnica de asociación libre de 


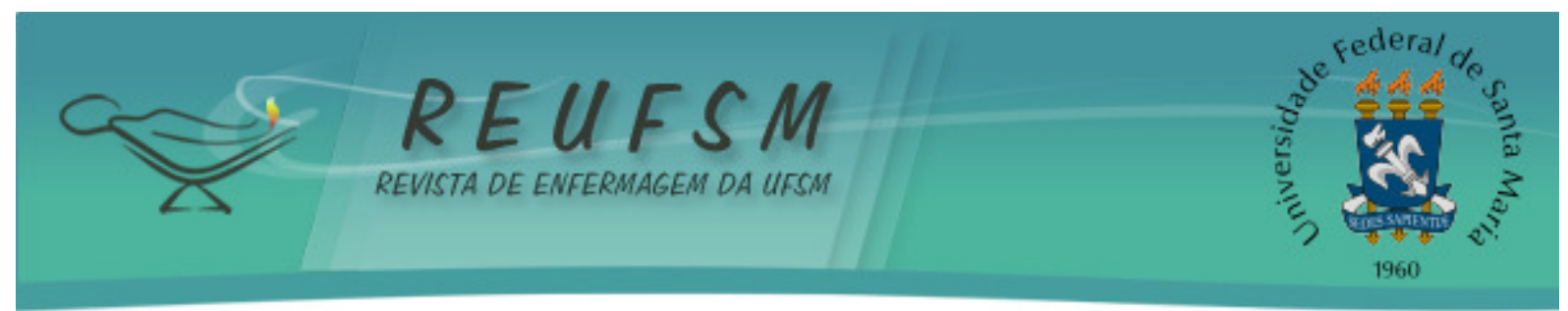

palabras y preguntas abiertas, con 134 adolescentes de la Unidad de Salud de Familia y analizados, a través de las representaciones sociales. Resultados: predominó edad 15-17 años, femenino, estudiantes, hasta octavo grado, solteros, ingreso familiar de 1 a 2 sueldos básicos. La mayoría nunca ha participado de grupos educativos. Las representaciones sociales de la salud están centralizadas en alimentación, bienestar y cuidar-cuidando. Con respecto a la enfermedad, están centralizadas en el dolor y la medicación. Conclusión: las representaciones sociales de la enfermedad se asocian con significados negativos, sin embargo, en relación a la salud predominancia positiva. Hay interés en participar en grupos de educación, abordando temas como sexualidad, drogas, proceso salud-enfermedad, prevención, deporte, educación y profesión.

Descriptores: Adolescente; Educación en salud; Enfermería.

\section{INTRODUÇÃO}

O conceito plural de adolescência engloba aspectos biológicos, emocionais e socioculturais. 0 componente biológico caracteriza-se pelas transformações anatômicas e fisiológicas, que incluem o crescimento e desenvolvimento e a maturação sexual. 0 aspecto emocional compreende as adaptações ao corpo em transformação, às novas relações com a família e outros grupos sociais e às novas experiências. O componente sociocultural abrange a busca da identidade adulta através de uma crescente autonomia e independência. Lidar com esta situação complexa exige das equipes multidisciplinares uma abordagem integral. ${ }^{1}$

Seguindo a orientação da Organização Pan-Americana de Saúde (OPAS), o Programa de Saúde do Adolescente vem procurando atuar de forma preventiva e incentivando atividades de promoção da saúde. ${ }^{2}$ Entretanto, percebe-se ainda dificuldade da sociedade em debater assuntos polêmicos, principalmente questões ligadas à sexualidade, prejudicando a divulgação de informações que poderiam favorecer a adoção de práticas saudáveis de vida. ${ }^{2}$ Por outro lado, os profissionais de saúde não encaram como sua a tarefa de participar na formação dos jovens, limitando-se ao atendimento de acordo com sua área de competência técnica. ${ }^{2} \mathrm{Na}$ maioria das vezes, não estão capacitados para prestar uma abordagem integral na atenção ao adolescente. Estas restrições impedem uma orientação adequada dos jovens e gera oportunidades perdidas de promoção da saúde. ${ }^{2}$

A adolescência é marcada por um comportamento resistente a orientações dos pais, devido a conjecturarem a possibilidade de ter controle sobre si mesmo. Dentro das atividades do trabalho em saúde coletiva, mais especificamente, na Estratégia Saúde da Família, a utilização do grupo como forma de assistência tem sido amplamente empregada, principalmente nos programas de saúde integral para doenças crônicas (hipertensão, diabetes), grupos de risco (DST e AIDS) e grupos de gestantes. 0 adolescente geralmente fica à margem desse processo educativo-assistencial, na medida em que são poucos os programas e grupos educativos (GE) que contemplem e/ou visem esta faixa etária especificamente, e os temas pertinentes à saúde-doença do adolescente ficam em segundo plano e ,raramente, são abordados tanto nos serviços de saúde quanto no âmbito familiar. ${ }^{3}$

Para análise dessa questão e com vistas ao planejamento de grupos educativos com adolescentes, é relevante a abordagem dos conhecimentos cotidianos que os atores sociais constroem sobre saúde-doença.

O referencial teórico que embasa esta pesquisa é a Teoria das Representações Sociais com maior ênfase na abordagem complementar denominada teoria do Núcleo Central. ${ }^{4}$ Sabemos que as representações sociais são elementos simbólicos que os homens expressam mediante o uso de palavras e de gestos. No caso do uso de palavras, utilizandose da linguagem oral ou escrita, os homens explicitam o que pensam, como percebem esta 


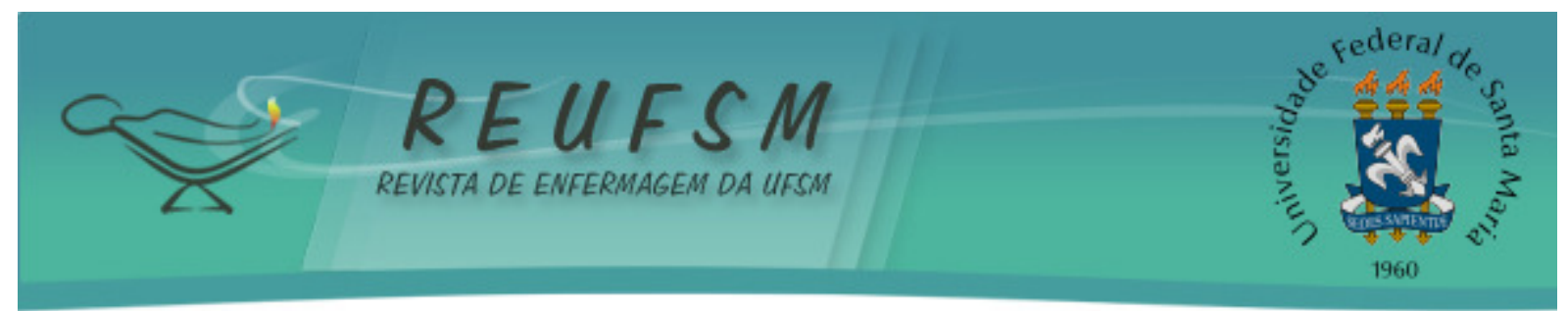

ou aquela situação, que opinião formula acerca de determinado fato ou objeto, que expectativas desenvolvem a respeito disto ou daquilo e assim por diante. Essas mensagens, mediadas pela linguagem, são construídas socialmente e estão, necessariamente, ancoradas no âmbito da situação real e concreta dos indivíduos que as emitem. ${ }^{5-6}$

Um estudo com representações sociais cita uma situação vivencial como, por exemplo, adolescentes grávidas ${ }^{7}$ e outro aborda as concepções dos profissionais de saúde construídas sobre a adolescência. Independente da abordagem, hoje vivenciamos uma nova interface da saúde para o adolescente com a criação da caderneta do adolescente e jovem, implantada no Pará desde 2010, além da criação do Programa Saúde na Escola, de 2007, o que dá mais voz ao jovem. Por isso, justifica-se esse estudo como uma forma de contribuir para um cuidar mais humanizado, dando oportunidade do adolescente ter poder de decisão e escolha no que tange a saúde. ${ }^{8}$

Assim, estudar as representações sociais é uma forma de entender o contexto social que esse grupo vivencia, visto que, estas expressam o processo historicamente construído por eles mesmos, permitindo uma análise contextual, se refletindo nos atos e posturas adotadas na diversidade das práticas sociais. ${ }^{9}$

0 estudo teve por objetivo conhecer as representações sociais sobre saúde e doença no olhar dos adolescentes.

\section{MÉTODO}

Trata-se de um estudo exploratório com abordagem qualitativa, fundamentado na Teoria das Representações Sociais (RS), utilizando a abordagem complementar Teoria do Núcleo Central. ${ }^{10} 0$ grupo de pesquisa Práticas Educativas em Saúde e Cuidado na Amazônia (PESCA) decidiu por uma escuta sensível, com adolescentes, para identificar seu perfil, a estrutura (central e periférica) das representações sociais sobre saúde-doença, bem como as demandas, opiniões e sugestões sobre participação em grupos educativos, por entender que primeiro é preciso conhecer o que pensam os adolescentes para depois, planejar e implementar uma intervenção educativa com eles. A partir desta situação problema, o PESCA realizou "escuta sensível" com os adolescentes de Benfica com vistas a obter respostas às seguintes questões norteadoras: Qual o perfil sócio-demográfico dos adolescentes do distrito de Benfica? Quais os pontos de vista dos adolescentes sobre participação em GE? Qual a estrutura (central e periférica) das Representações sobre saúde e doença dos adolescentes?

Os sujeitos foram 134 adolescentes entre 12 e 19 anos cadastrados na Unidade de Saúde da Família Paraíso, localizada no Distrito do Murinin, Benevides, Pará. Os critérios de seleção foram: adolescentes de 12 a 19 anos cadastrados na unidade de saúde da família Paraíso do Murunim. Para coletar os dados aplicou-se a técnica de evocações livres de palavras com os termos indutores saúde-doença. Aplicou-se um formulário individual, com questões abertas e fechadas, após autorização dos pais ou responsáveis legais que assinaram o Termo de Consentimento Livre e Esclarecido.

As evocações foram processadas no software EVOC 2003 para favorecer a análise estrutural das representações sociais, a partir da qual foram propostas hipóteses acerca da centralidade dos conteúdos das representações. O projeto foi aprovado pelo Comitê de Ética e Pesquisa da Universidade do Estado do Pará sob nº 0008.0.321.000.09.

\section{RESULTADOS}

Os 134 adolescentes estão na faixa etária de 12 a 19 anos, divididos em grupos de $12-14 ; 15-17$ e maior que 18 , correspondendo, respectivamente, $43,9 \% ; 48,7 \%$ e $7,4 \%$. 




Quanto ao gênero, os do sexo feminino $(61,9 \%)$ foram mais evidenciados. Segundo a escolaridade, prevaleceram sujeitos com até a $8^{\text {a }}$ serie $(65,7 \%)$. No que se refere à ocupação, há uma predominância para aqueles que apenas estudam $(82,9 \%)$. Quanto ao estado civil, a grande maioria é de solteiros (94\%).

No que se refere à moradia, a maioria reside com os pais $(73,1 \%)$. Segundo a ocorrência de filhos, a grande maioria não possui filhos (91\%). Para os sujeitos, o maior meio de informação é a televisão $(59,6 \%)$. No que tange a distribuição segundo a renda familiar, a que mais se destacou foi 1-2 salários mínimos (64,1\%). Quanto a possuírem plano de saúde, a grande maioria não tem (90,2\%), como mostra a Tabela 1.

Tabela 1 - Perfil dos adolescentes - sujeitos do estudo

\begin{tabular}{lcc}
\hline Variável & Categoria em grupo & Percentual de adolescentes \\
\cline { 2 - 3 } Gênero & Feminino & $61,9 \%$ \\
Escolaridade & Até a 8 $8^{\text {a }}$ série & $65,7 \%$ \\
Ocupação & Estuda & $82,9 \%$ \\
Estado Civil & Solteiro & $94 \%$ \\
Moram com & Pais & $73,1 \%$ \\
Possui Filhos & Sim & $9 \%$ \\
Meio de Informação & Televisão & $59,6 \%$ \\
Renda Familiar & 1 a 2 salários & $64,1 \%$ \\
Plano de Saúde & Não & $90,2 \%$ \\
\hline
\end{tabular}

Sobre a participação em GE não há diferença significativa entre quem não participou $(50,7 \%)$ e quem já participou ou participa $(49,3 \%)$; sobre os locais dos GE frequentados o que mais se destacou foi a igreja $(56,7 \%)$; no que se refere aos tipos de grupos, os mais citados foram grupos de igreja $(26,5 \%)$ e grupo de coral $(22,4 \%)$.

A maioria dos adolescentes referiu que gostaria de participar de algum GE $(92,5 \%)$. Os melhores dias indicados foram sábado (26\%), sexta (15\%) e quarta-feira (14,5\%); sobre a quantidade de encontros por semana, os mais escolhidos foram $2(35 \%)$ e $1(30,6 \%)$ vez, respectivamente.

O local para os encontros que mais se destacou foi a área externa da unidade de saúde $(58,1 \%)$; outro local fora da unidade bom para os GE que se destacou foi a escola $(29,1 \%)$; sobre os melhores horários não houve diferença significativa entre manhã $(57,2 \%)$ e tarde $(43,9 \%)$; sobre as informações que gostariam de debater ficaram em evidencia os temas "saúde-prevenção e atendimento" $(42,9 \%)$ e "aspectos sócio-relacionais" $(22,9 \%)$, como mostra a Tabela 2.

Tabela 2 - Pontos de vista dos adolescentes sobre a participação em grupo educativo

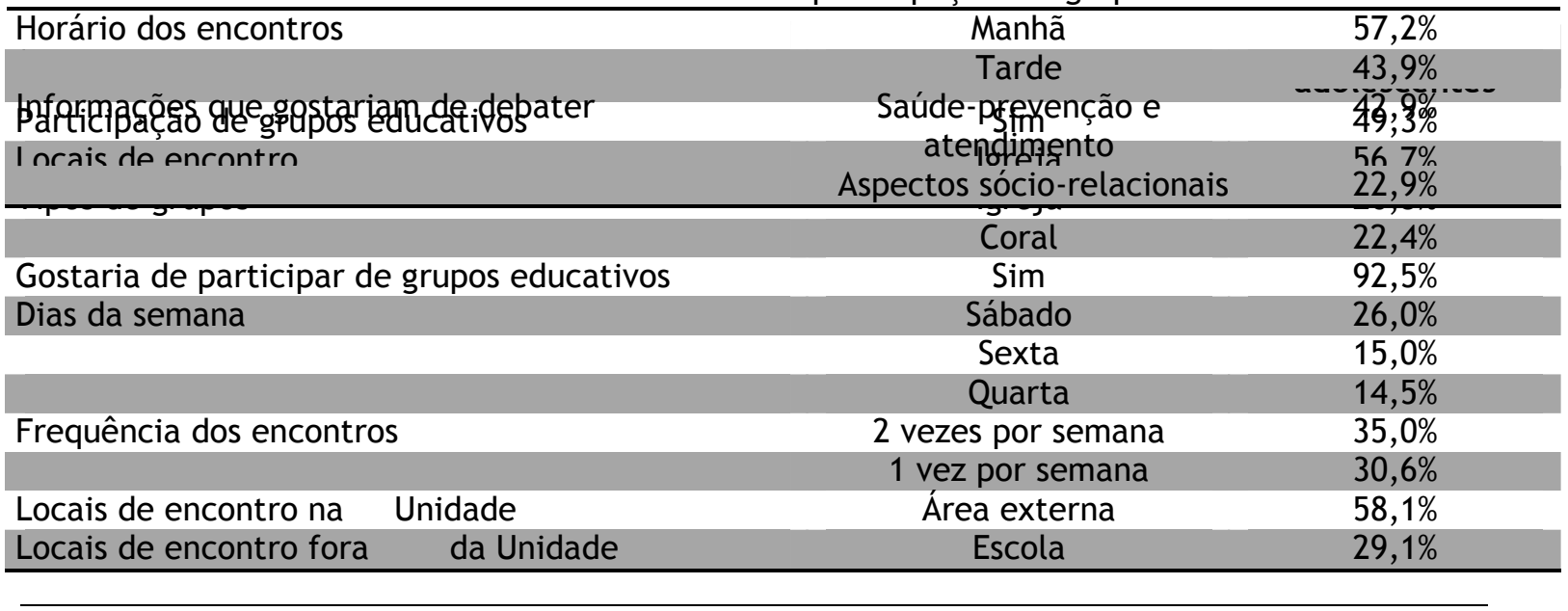




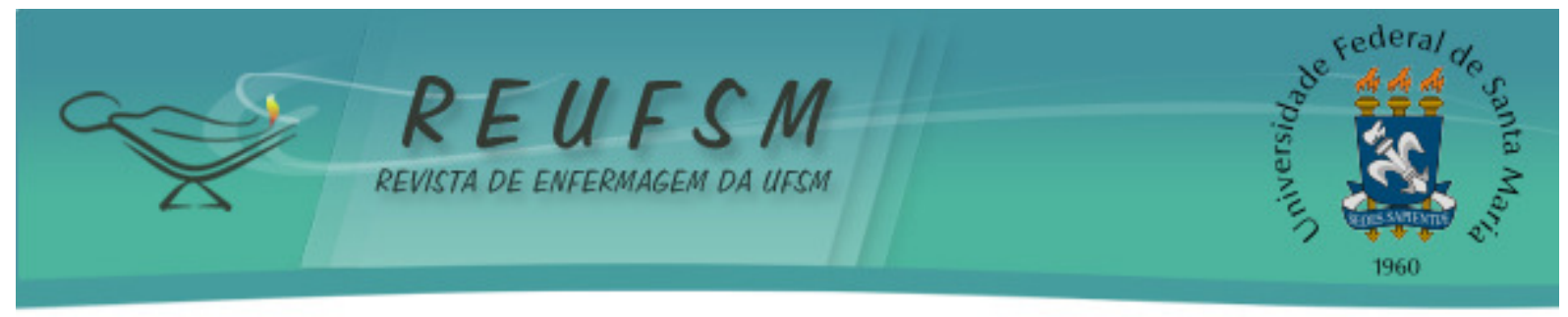

As informações que gostariam de debater foram agrupadas em sete eixos-temas: saúde-prevenção e atendimento; aspectos sócio-relacionais; outros assuntos; educação e cursos gerais; violência e drogas; artesanato e informática. Os dois eixos-temas com mais citações foram - saúde-prevenção e atendimento e aspectos sócio-relacionais. Constatouse que a grande maioria dos jovens manifestou interesse em participar de GE.

As evocações dos adolescentes sobre SAÚDE possibilitaram a construção do quadro de quatro casas (Quadro 1).

Quadro 1 - Quadro de quatro casas das evocações ao termo-expressão "o que é saúde"

\begin{tabular}{|c|c|c|c|c|c|c|}
\hline O.M.E & \multicolumn{3}{|c|}{ Rang $<3,3$} & \multicolumn{3}{|c|}{ Rang $>3,3$} \\
\hline $\begin{array}{l}\text { Frequência } \\
\text { Média }\end{array}$ & $\begin{array}{l}\text { Termo } \\
\text { Evocado }\end{array}$ & Freq. & O.M.E & $\begin{array}{l}\text { Termo } \\
\text { Evocado }\end{array}$ & Freq. & O.M.E \\
\hline$\geq 24$ & $\begin{array}{l}\text { Núcleo Central } \\
\text { Alimentaçãao } \\
\text { Bem-estar } \\
\text { Cuidar-cuidado }\end{array}$ & $\begin{array}{l}32 \\
42 \\
48\end{array}$ & $\begin{array}{l}2,469 \\
2,381 \\
2,042\end{array}$ & $\begin{array}{c}1^{\circ} \text { Periferia } \\
\text { Médico }\end{array}$ & 25 & 2,840 \\
\hline$\leq 14$ & $\begin{array}{c}\text { Zona de contraste } \\
\text { Felicidade } \\
\text { Prevenção } \\
\text { Vida }\end{array}$ & $\begin{array}{l}22 \\
21 \\
15\end{array}$ & $\begin{array}{l}2,227 \\
2,286 \\
1,933\end{array}$ & $\begin{array}{c}2^{\circ} \text { Periferia } \\
\text { Alegria } \\
\text { Doença } \\
\text { Exercício } \\
\text { Hospital } \\
\text { Remédio }\end{array}$ & $\begin{array}{l}20 \\
17 \\
19 \\
14 \\
14\end{array}$ & $\begin{array}{l}2,650 \\
2,882 \\
2,632 \\
2,643 \\
3,143\end{array}$ \\
\hline
\end{tabular}

1 - Ordem média de evocação (OME)

Foram coletadas 106 palavras diferentes (480 evocações no total) ao termo o que é saúde. As palavras mais frequentes e hierarquizadas nos primeiros lugares ocuparam o quadrante superior esquerdo, que indica os conteúdos do provável núcleo central. 0 que é central nas Representações Socais dos adolescentes sobre "Saúde" é: alimentação, bemestar e cuidar-cuidado. Destaca-se o termo "cuidar-cuidado" que obteve 48 citações.

0 sistema periférico é constituído dos seguintes termos: na $1^{\mathrm{a}}$ periferia encontramos o termo médico, com 25 citações; na $2^{a}$ periferia encontramos os termos alegria, doença, exercício, hospital e remédio com destaque para o termo "alegria", que obteve 20 citações; na zona de contraste encontramos os termos felicidade, prevenção e vida, com destaque para o termo felicidade que obteve 22 citações.

As evocações dos adolescentes sobre DOENÇA possibilitaram a construção do quadro de quatro casas (Quadro 2).

Quadro 2 - Quadro de quatro casas das evocações ao termo-expressão "o que é doença"

\begin{tabular}{|c|c|c|c|c|c|c|}
\hline O.M.E & \multicolumn{2}{|c|}{ Rang< 3,3 } & \multicolumn{3}{c|}{ Rang $>3,3$} \\
\hline $\begin{array}{c}\text { Frequência } \\
\text { Média }\end{array}$ & $\begin{array}{c}\text { Termo } \\
\text { Evocado }\end{array}$ & Freq. & O.M.E & $\begin{array}{c}\text { Termo } \\
\text { Evocado }\end{array}$ & Freq. & O.M.E \\
\hline 22 & $\begin{array}{c}\text { Núcleo Central } \\
\text { Dor } \\
\text { Medicamento }\end{array}$ & 53 & 2,528 & $\begin{array}{c}1^{\circ} \text { Periferia } \\
\text { Triste } \\
2,353\end{array}$ & 46 & 2,826 \\
\hline
\end{tabular}




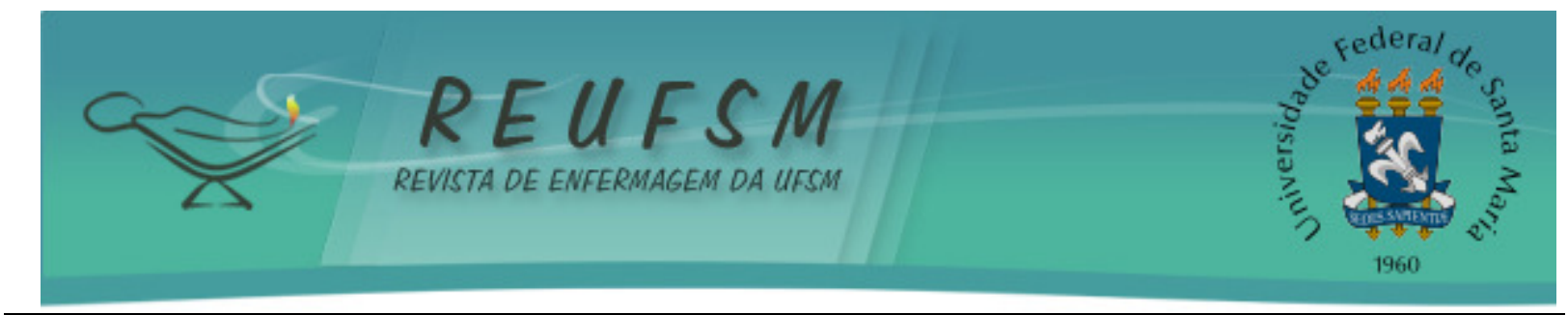

\begin{tabular}{|c|c|c|c|c|c|c|}
\hline & Zona de contraste & & & 2 $^{\circ}$ Periferia & & \\
& Cuidado & 16 & 2,063 & DST & 15 & 2,600 \\
& Falta & 10 & 1,800 & Mal-estar & 15 & 2,933 \\
& Febre & 19 & 2,211 & Morte & 17 & 2,882 \\
& Gripe & 9 & 2,556 & & & \\
& Hospital & 17 & 2,000 & & & \\
& Médico & 19 & 2,053 & & & \\
& Prevenção & 15 & 2,467 & & & \\
\hline
\end{tabular}

1 - Ordem média de evocação (OME)

Para o estímulo "o que é doença”, foram coletadas 116 palavras diferentes (511 evocações no total). As palavras mais frequentes e que foram hierarquizadas nos primeiros lugares foram dor e medicamento. Destaca-se o termo “dor” com 53 citações.

O sistema periférico é constituído dos seguintes termos: na $1^{\mathrm{a}}$ periferia o termo "tristeza" com 46 citações; na $2^{\mathrm{a}}$ periferia os termos: DST, mal-estar e morte; com destaque para o termo "morte" que obteve 17 citações; na zona de contraste, os termos: cuidado, falta, febre, gripe, hospital, médico e prevenção; com destaques para os termos "febre e médico" obtendo 19 citações cada.

\section{DISCUSSÃO}

A estrutura (central e periférica) da RS de "Saúde" entre os adolescentes nos remete a pensar que para os adolescentes, saúde localiza-se na interface alimentação, bem-estar e cuidar-cuidado. ${ }^{11}$ A RS centra-se em seu núcleo, neste sentido, no cuidar-cuidado, termo mais saliente, que aparece como essencial, podendo implicar em ações que evitem doenças ou que promovam saúde. Nesse sentido, cuidar é atuar sobre o poder de existir, é possibilitar a liberação da capacidade de cada ser humano para existir e para viver, cuidar é definitivamente uma forma de promover a vida, e consequentemente, a saúde. ${ }^{12}$

A estrutura da representação não revela nenhum léxico de oposição; a palavra doença parece manter a tensão do processo saúde-doença. O processo saúde-doença é o processo que envolve o adoecimento e cura, sendo influenciado pelo seu contexto social e pelos paradigmas que regem a saúde e a doença, atualmente, o processo saúde-doença caracteriza-se pelas relações entre o homem e a natureza (meio ambiente, espaço e território) e entre outros homens (relações sociais, culturais e políticas), sendo assim um processo social. ${ }^{13}$

A estrutura (central e periférica) da RS de "Doença” entre os adolescentes nos remete a pensar que a representação localiza-se no entremeio entre dor e medicamento. A palavra dor aparece como essencial, estando relacionada aos sintomas mais presentes durante o processo da doença. Medicamento é toda substância ou associação de substâncias que possui propriedades curativas ou preventivas de doenças ou dos seus sintomas, utilizado ou administrado com vistas a exercer ação farmacológica, imunológica ou metabólica, a restaurar, corrigir ou modificar funções fisiológicas. ${ }^{14} \mathrm{~A}$ estrutura da representação não revela nenhum léxico de oposição, pois todas as palavras mencionadas estão relacionadas direta ou indiretamente com o termo-indutor.

Estudo com adolescentes revela que as representações sociais dos adolescentes sobre saúde permearam a interface bem-estar e cuidar-cuidado, chegando a destacar as palavras felicidade, alegria e alimentação saudável, entre outras mencionadas pelos jovens. Também expressaram os termos médico, remédio e prevenção no que se refere ao processo saúde-doença. ${ }^{15}$ No mesmo estudo é evidente que as representações sociais de saúde e doença vão além de fatores biológicos, sendo frequente as questões sóciorelacionais como fatores do processo saúde-doença. ${ }^{15}$ 


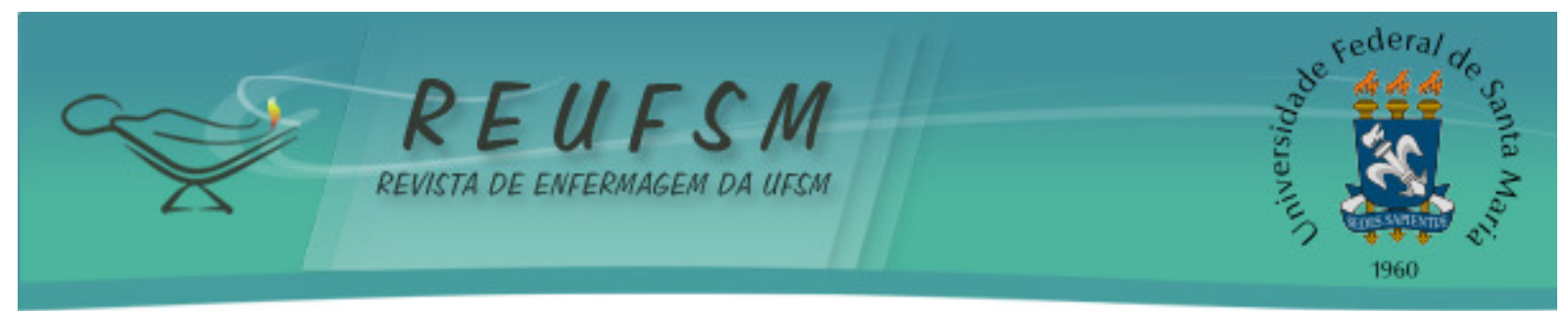

Quanto ao comportamento dos sujeitos, há vontade social para o trabalho em GE, pois apontaram local, espaço a ser ocupado, sugestões sobre os temas a serem debatidos e horários mais viáveis para o desenvolvimento das atividades.

$\mathrm{Na}$ distribuição dos temas relacionados, saúde-prevenção e atendimento aparece em primeiro plano, seguido das necessidades sócio-relacionais, reforçando a visão quanto ao desejo do grupo de encontrar caminhos para a mudança. Entendemos ser este um desafio para a educação em saúde com adolescentes.

Outros estudos apontam que apesar do receio inicial por parte dos adolescentes, as ações educativas estimulam o compartilhamento de conhecimentos e de experiências entre os integrantes, e quando a discussão está pautada em questões de interesse desse público e contextualizada no seu meio cultural e socioeconômico, promove a construção de um espaço sistêmico e circular. Neste caso, o facilitador apresenta-se como uma figura reveladora e inspiradora já que permite esse elo entre emergência de uma prática convergente com o contexto sociocultural dos adolescentes. ${ }^{16}$

Há interesse dos adolescentes por essas atividades quando disponibilizadas, e que quando há envolvimento deles nessas atividades, ocorre redução de violência, prevenção de envolvimento com drogas, bom desempenho escolar, bom relacionamento familiar e convívio com os amigos. ${ }^{17}$

Portanto, é fundamental o direcionamento de ações para empoderar os adolescentes sobre os seus direitos de acesso aos serviços de promoção da saúde, para que se possa ser direcionada uma cultura que integre o ambiente escolar aos demais eixos correlatos à dinâmica de vida do adolescente, a saber: a família, os grupos de amigos, a equipe de saúde e a comunidade. ${ }^{18}$

\section{CONCLUSÕES}

As representações sociais dos adolescentes sobre doença estão relacionadas direta ou indiretamente com sentidos negativos. Com relação à saúde há uma predominância positiva e a palavra doença parece manter a tensão saúde/doença entre dois polos. Percebe-se que há um significativo interesse dos adolescentes em participar de grupos educativos e que as demandas são em torno de questões relacionadas com a sexualidade, o uso de drogas, o processo saúde-doença, meios de prevenção, esporte, educação e profissão. Ações educativas realizadas com adolescentes devem ter, como objetivo, promover a tomada de decisão em relação às ações de saúde, bem como resgatar a cidadania destes sujeitos durante o processo educativo, o que possibilita a implantação de programas de atendimento educativo mais específicos e políticas que atendam suas necessidades. Estudos com adolescentes sobre saúde permitem a aproximação do profissional enfermeiro com a realidade e os conhecimentos cotidianos deste grupo, oportunizando desenvolver práticas educativas que possam promover saúde com o objetivo de tornar esta etapa da vida mais saudável e estes jovens protagonistas do seu cuidarcuidado.

\section{REFERÊNCIAS}

1. Brasil. Ministério da Saúde. Secretaria de Políticas de Saúde Assistência à Saúde. A saúde de adolescentes e jovens: uma metodologia de auto-aprendizagem para equipes de atenção básica de saúde. Módulo I. Brasília: Ministério da Saúde; 2000.

2. Ruzany MH. Adolescência e promoção de saúde. Rio de Janeiro: Universidade do Estado do Rio de Janeiro/Núcleo de Estudos da Saúde do Adolescente; 1994. (mimeo). 


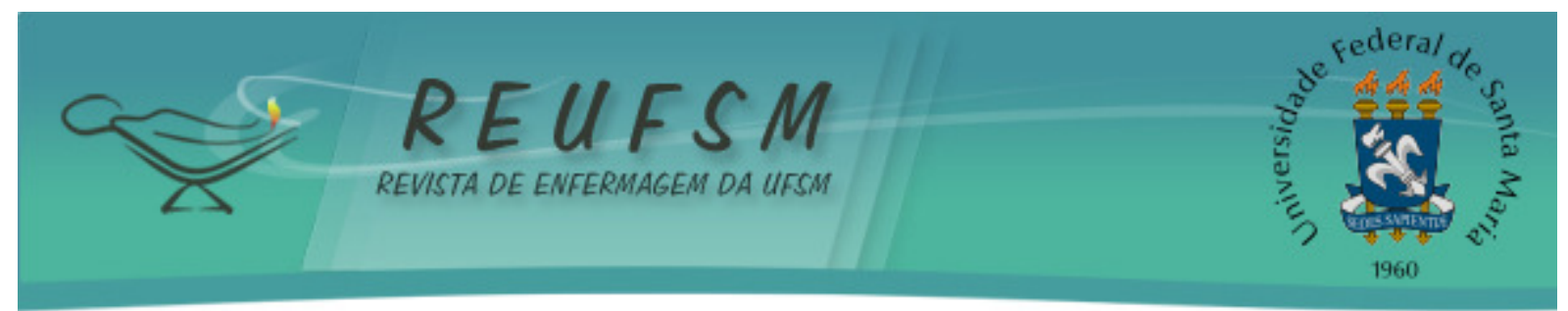

3. Szwarcwald CL. Oportunidades perdidas na atenção ao adolescente. Adolesc Latinoam. 2000;2(1):26-35.

4. Brasil. Ministério da Saúde. Secretaria de Atenção à Saúde. Departamento de Atenção Básica. HIV/AIDS, hepatites e outras DST. Brasília: Ministério da Saúde; 2006.

5. Sá CP. Núcleo central das representações sociais. Petrópolis (RJ): Vajes; 1996.

6. Moscovici S. La psychanalyse, son image et son publico. $2^{\mathrm{a}}$ ed. Paris: PUF; 1976.

7. Albuquerque-Souza AX, Nóbrega SM, Coutinho MPL. Representações sociais de adolescentes grávidas sobre a gravidez na adolescência. Psicol Soc. 2012;24(3):588-96.

8. Fonseca DC, Ozella $S$. As concepções de adolescência construídas por profissionais da Estratégia de Saúde da Família (ESF). Interface Comun Saúde Educ. 2010;14(33):411-24.

9. Franco MLPB. Representações sociais, ideologia e desenvolvimento da consciência. Cad Pesqui. 2004;34(121):169-86.

10. Oliveira RF, Silva NMA. Representação social de adolescentes sobre sexualidade: posicionamento em sala de aula. In: Anais do $10^{\circ}$ Congresso Nacional de Educação; 2011; nov 07-10; Curitiba. Curitiba: EDUCERE; 2011.

11. Oliveira DC, Gomes AMT, Pontes APM, Salgado LPP. Atitudes, sentimentos e imagens na representação social da sexualidade entre adolescentes. Esc Anna Nery Rev Enferm [Internet]. 2009 [acesso em 2013 abr 10];13(4):817-23. Disponível em: www.scielo.br/pdf/ean/v13n4/v13n4a18.

12. Reis AT, Oliveira DC, Gomes AMT. Representações sociais sobre saúde entre adolescentes de escolas públicas do município do Rio de Janeiro. Rev Enferm UERJ. 2009;17(4):473-8.

13. Fragoso V. A arte de cuidar e ser cuidado: cuidar-se para cuidar. Rev Enferm UERJ [Internet]. 2006 [acesso em 2013 jun 5];3(5)[8 telas]. Disponível em: www.igt.psc.br/ojs/include/getdoc.php?id=719\&article=21\&mode.

14. Tancredi FB, Barrios SRL, Ferreira JHG. Planejamento em Saúde. São Paulo: Universidade de São Paulo, Faculdade de Saúde Pública; 1998. (Saúde \& Cidadania; v.2).

15. Brasil. Ministério da Saúde. Decreto-Lei $n^{\circ} 176$, de 30 de agosto de 2006. Estatuto do Medicamento [Internet]. 2006 [acesso em 2013 abr 10]. Disponível em: www.dre.pt/pdf1s/2006/08/16700/62976383.pdf.

16. Tavares LI, Lima SK, Lima ADF, Costa FMM, Cunha VNF, Costa PPN. Ações educativas desenvolvidas por enfermeiros brasileiros com adolescentes vulneráveis às DST/AIDS. Cienc Enferm [Internet]. 2012 [acesso em 2013 abr 10];18(1):43-55. Disponível em: www.scielo.cl/scielo.php?script=sci_arttext\&pid=S0717-95532012000100005.

17. Oliveira LG, Brum ZP, Oliveira SG, Wünsch S, Garcia RP, Simon BS, et al. Oferta de serviços assistenciais aos adolescentes em seis municípios da $12^{\mathrm{a}}$ Coordenadoria Regional de Saúde. Rev Enferm UFSM [Internet]. 2012 [acesso em 2013 abr 10];1(3):335-42. Disponível em: http://cascavel.ufsm.br/revistas/ojs2.2.2/index.php/reufsm/article/view/3584/2382.

18. Maia LLQGN, Araújo A, Santos Jr AS. Motivações para a violência no contexto escolar sob a ótica do adolescente. Rev Enferm UFSM [Internet]. 2012 [acesso em $2013 \mathrm{abr}$ 10];2(1):20-31. Disponível em: http://cascavel.ufsm.br/revistas/ojs2.2.2/index. php/reufsm/article/download/3760/3123. 
Data de recebimento: 15/06/2013

Data de aceite: $21 / 01 / 2014$

Contato com autor responsável: Elizabeth Teixeira

Endereço postal: Avenida José Bonifácio, N 1289 - São Brás. CEP: 66063-010

Belém, PA - Brasil.

E-mail: etfelipe@hotmail.com 